Artigo Científico Original

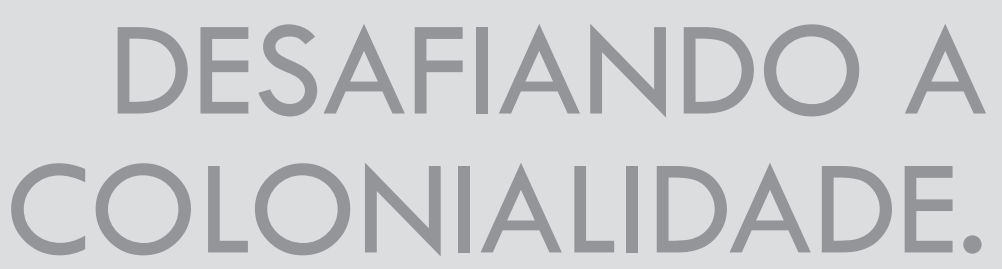

A ECOLOGIA DE JUSTIÇAS COMO INSTRUMENTO DA DESCOLONIZAÇÃO JURÍDICA

Sara Araújo 
DESAFIANDO A

COLONIALIDADE. A

ECOLOGIA DE JUSTIÇAS

COMO INSTRUMENTO

DA DESCOLONIZAÇÃO

JURÍDICA ${ }^{1}$
CHALLENGING

COLONIALITY. ECOLOGY

OF JUSTICES AS AN

INSTRUMENT FOR LEGAL

DECOLONIZATION

\section{Sara Araújo}

Investigadora do Centro de Estudos Sociais da Universidade de Coimbra e membro do Núcleo de Estudos sobre Democracia, Cidadania e Direito. É co-coordenadora do Projeto "ALICE, Espelhos Estranhos, Lições Imprevistas: Definindo para a Europa uma nova forma de partilhar as experiências do mundo", onde vem sendo desenvolvida reflexão e investigação a partir das propostas das Epistemologias do Sul. Doutorou-se em "Direito, Justiça e Cidadania no século XXI" da Universidade de Coimbra, com a tese "Ecologia de Justiças a Sul e a Norte. Cartografias comparadas das justiças comunitárias em Maputo e em Lisboa". Defendeu uma tese de Mestrado em Sociologia com o título "Pluralismo Jurídico e acesso à Justiça. O papel das instâncias comunitárias de resolução de conflitos em Moçambique", distinguida com o Prémio Agostinho da Silva, atribuído pela Academia de Ciências de Lisboa. Fez parte do Observatório Permanente da Justiça Portuguesa e do Centro de Formação Jurídica e Judiciária de Moçambique. Os seus interesses de investigação centram-se nos seguintes temas: pluralismo jurídico, acesso à justiça, justiça comunitária/resolução alternativa de conflitos/justiça informal, administração da justiça em África, direitos humanos e interculturalidade, ecologia de saberes e de justiças.

\section{RESUMO}

Este texto resulta de uma investigação, assente na proposta das Epistemologias do Sul de Boaventura de Sousa Santos, que tem como objetivo contribuir para $\circ$ debate sobre o alargamento do cânone do direito e da justiça e a construção de um pensamento jurídico pós-abissal. Partindo do conceito de ecologia de saberes, proponho a ideia de ecologia de justiças como instrumento epistemológico para confrontar a conceção moderna do direito e da justiça e as hierarquias impostas pelo cânone com a diversidade de direitos e de justiças que existem no mundo, contribuindo para o conhecimento e a valorização da diversidade que cabe no interior do conceito de pluralismo jurídico. Argumento que o Sul é heterogéneo, que a sociologia jurídica das ausências e das emergências requer instrumentos epistemológicos e me-

\section{ABSTRACT}

This paper is the outcome of a research grounded on Boaventura de Sousa Santos' Epistemologies of the South that aims to contribute to the debate on the extension of the canon of law and justice and towards the building of a post-abyssal legal thinking. Based on the concept of ecology of knowledges, I propose the idea of ecology of justices as an epistemological instrument to oppose the modern conception of law and justice and the hierarchies imposed by the canon with the diversity of laws and justice that exist in the world, contributing towards the knowledge and valorisation of diversity that conforms with the concept of legal pluralism. I argue that the South is heterogeneous, that the legal sociology of absences and emergencies requires epistemological and methodological instru- 
todológicos sensíveis aos contextos e que um pensamento jurídico pós-abissal deve estender-se para lá do que foi identificado como legalidade cosmopolita, incluindo espaços de reivindicação de direitos em que as lutas não se expressam nas categorias emancipatórias que conhecemos. Concluo o texto com a apresentação de uma cartografia das justiças comunitárias no centro da cidade de Maputo, com a qual pretendo ilustrar o percurso metodológico e os resultados da ecologia de justiças.

Palavras-chave: Epistemologias do Sul, pensamento jurídico pós-abissal, ecologia de justiças, pluralismo jurídico, cartografias jurídicas ments sensitive to the contexts and that a post-abyssal legal thinking should extend beyond what has been identified as cosmopolitan legality, including struggles that are not expressed in the emancipatory categories we know. I conclude by presenting a map of community justices in the centre of Maputo, with the intention of illustrating the methodological approach and the outputs of an ecology of justices.

Keywords: Epistemologies of the South, post-abyssal legal thinking, ecology of justices, legal pluralism, legal cartographies.

\section{INTRODUÇÃO}

O colonialismo europeu não foi apenas um projeto económico e político, que envolveu a exploração de recursos e a dominação política de povos, tendo terminado com as descolonizações formais. Deixou um legado de injustiça, assente na colonialidade do poder (Quijano, 2009), alimentado por uma estrutura colonizadora responsável pela marginalização de sociedades, culturas e seres humanos (Mudimbe, 1988). Se as relações políticas mudaram com o fim político dos impérios coloniais, as narrativas hegemónicas sobre as quais assentou a alegada superioridade dos países do Norte não foram decisivamente postas em causa e são constitutivas do projeto da modernidade. Ainda que seja estabelecida uma horizontalidade política formal, enquanto couber a uma das partes a definição da linguagem e dos termos do que conta como válido, os saberes e as práticas que se exprimem de outro modo tendem a ser inferiorizados e invisibilizados.

A metáfora do pensamento abissal usada por Boaventura de Sousa Santos para caracterizar o pensamento moderno é umas das mais interessantes ilustrações da colonialidade. Para o autor, - pensamento moderno ocidental é um pensamento abissal, que assenta em distinções visíveis e invisíveis. As distinções invisíveis são estabelecidas através de linhas radicais, que impedem a copresença do universo "deste lado da linha" com o universo "do outro lado da linha". O outro lado, mais do que irrelevante, é produzido como não existente. Tornada invisível, a realidade do lado lá não compromete a universalidade do que vale apenas do lado de cá e configura no seu conjunto um leque alargado de experiência desperdiçada. A linha abissal não é uma marcação geográfica, que separa territórios que foram colonizados de países que foram colonizadores. Trata-se de uma divisão entre o Norte e o Sul enquanto metáforas das Epistemologias do Sul, sendo reconhecido que o Sul metafórico existe no norte geográfico e o Norte metafórico existe no sul geográfico. O Sul expressa o sofrimento humano causado pelo capitalismo, pelo colonialismo e pelo pa- 
triarcado, bem como a resistência para ultrapassar ou minimizar esse sofrimento (Santos, 1995, 2007).

Juntando-se a um conjunto de formulações críticas da colonialidade, as Epistemologias do Sul abraçam o desafio epistemológico de desenvolver um pensamento pós-abissal. Assentam numa proposta de transformação do modo de produzir conhecimento, fundamentada em premissas como as de que a compreensão do mundo excede em muito a compreensão ocidental do mundo e que muita da diversidade é desperdiçada, porque as teorias e os conceitos desenvolvidos no Norte global e usados em todo o mundo académico excluem grande parte dessa diversidade e contraem - mundo, tornando-o mais pequeno e menos diverso (Santos e Meneses, 2009; Santos, $2012 a$ ).

Este texto pretende contribuir para a reflexão e o debate sobre o alargamento do cânone do direito e da justiça e a construção de um pensamento jurídico pós-abissal. Partindo do conceito de ecologia de saberes, proponho o conceito de ecologia de justiças como instrumento epistemológico para confrontar a conceção moderna do direito e da justiça e as hierarquias definidas em função do cânone moderno com a diversidade de direitos e de justiças que existem no mundo. Começo por mostrar de que modo a ciência e o direito foram os principais instrumentos de criação do pensamento abissal. Ainda que Boaventura de Sousa Santos reflita largamente sobre a simbiose entre direito e ciência na construção do mundo moderno colonial e desenvolva uma proposta de direitos humanos interculturais (Santos, 1995, 2000, 2002, 2007, 2009), na teoria da superação da linha abissal não desenvolve aprofundadamente os princípios da descolonização do direito, centrando-se sobretudo nos desafios à monocultura do saber e do rigor do saber. Assim, no segundo ponto, procuro contribuir para essa reflexão, nomeadamente com a identificação de instrumentos epistemológicos que rompam com a hegemonia do direito moderno e permitam ampliar as experiências jurídicas conhecidas. Antes de entrar na terceira parte, defino os objetivos de superar os estudos tradicionais do pluralismo jurídico, reconhecer a heterogeneidade do Sul e construir um pensamento pós-abissal cada vez mais inclusivo, que identifique e inclua a legalidade cosmopolita, mas também outros espaços onde as lutas não se expressam nas categorias emancipatórias que as ciências sociais reconhecem. Finalmente, mostro como atuam os instrumentos epistemológicos identificados, recorrendo à ilustração de uma cartografia de justiças comunitárias realizada no centro urbano da cidade de Maputo, em Moçambique.

\section{ODIREITOEA CIÊNCIANA CONSTRUÇÃO}

\section{DO PENSAMENTO ABISSAL}

A vitória do conhecimento científico, transformada em "emblema da modernidade" (Quijano, 2009), prendeu-se com as necessidades cognitivas do capitalismo na sua obsessão pelo conhecimento que se traduz em desenvolvimento tecnológico (Santos et. al., 2004). Assim, passou a caber à ciência moderna o privilégio de definir o que é conhecimento válido e a história fez-se da negação da diversidade e da subalternização de grupos sociais cujas práticas assentam em conhecimentos desvalorizados pelo cânone ocidental. Esta realidade, expressa no conceito de "colonialidade do saber" (Castro-Gómez, 2007), foi classificada como "epistemicídio" (Santos, 1995), "injustiça cognitiva global" (Santos, 2006) ou "violência epistémica do imperialismo" (Spivak, 1988). 
O direito moderno foi o duplo da ciência e se esta legitimou o "epistemicídio", a conceção moderna de direito enquanto direito do Estado promoveu um "juricídio" (Santos, 1995, 2011). A Norte ou a Sul, as sociedades sempre foram juridicamente plurais e palco de múltiplas instâncias de resolução de conflitos. A justaposição entre direito, Estado e nação ou entre justiça e tribunais judiciais foi uma particularidade introduzida pela modernidade. A versão moderna do direito e da justiça desenvolveu-se numa visão monista ou centralista ao serviço dos princípios e valores do projeto liberal e capitalista, como a igualdade, a unidade política, a segurança jurídica, a liberdade individual e a ordem (Galanter, 1966; Griffiths J., 1986; Hespanha, 1993, 2007; Wolkmer, 1994; Santos, 2000, 2009). O recente reconhecimento de que o pluralismo jurídico aufere não significa que as hierarquias tenham sido ameaçadas. Evocando uma metáfora usada recentemente, o direito estatal ainda é considerado o centro do universo e não apenas mais um dos planetas (Janse, 2013). Se a colonialidade que comprimiu o conhecimento assume a forma de colonialidade do saber, a colonialidade que comprimiu o mundo jurídico pode ser designada como colonialidade jurídica ou colonialidade do direito.

Direito e a ciência, unidos, converteram-se em instância moral suprema, acima do bem e do mal, sustentando o mito do crescimento linear infinito e a obsessão com a ideia de progresso (Santos, 2000). A narrativa moderna ignorou que o caminho escolhido era apenas uma entre as múltiplas opções válidas e que o saber e o direito em que assentava configuravam apenas uma pequena parte do conhecimento e do direito do mundo. A urgência da descolonização epistémica é transversal às várias áreas do conhecimento e, nesse sentido, é importante pensá-la no âmbito dos múltiplos objetos das ciências sociais. A sociologia do direito tem a particularidade de ter como objeto um dos instrumentos de construção de hierarquias e de classificação do outro como inferior, atrasado, primitivo. Assim, em primeiro lugar, é necessário descolonizar os estudos da sociologia do direito e, em segundo lugar, descolonizar o próprio direito, sendo que um passo dado no âmbito do primeiro objetivo constitui um contributo para o segundo. Consciente que estas metas só poderão ser alcançadas coletivamente e num esforço continuado de renovação e transformação do pensamento, é no horizonte destes ambiciosos objetivos que se situa esta reflexão.

\subsection{A ciência moderna e a contração do mundo}

A alegada universalidade da ciência moderna não é mais do que um "localismo globalizado" (Santos, 2001; 2008)2, construído a partir de um "etnocentrismo epistemológico" (Mudimbe, 1988) ou "eurocentrismo" (Quijano, 2009), que promove a "falácia do deslocamento" (Dussel, 2013 3), a "falácia do determinismo" e a "falácia do desaparecimento do Sul", e assenta numa "razão indolente" (Santos, 2000)", que alimentou a "epistemologia da cegueira" (idem) ou a "epistemologia do ponto zero" (Castro-Gómez, 2007).

A hierarquia dos saberes e dos sujeitos é uma armadilha produzida por um conjunto de lógicas que foram interiorizadas não apenas pelo colonizador, mas também pelo colonizado. As experiências eurocêntricas são entendidas como naturais,

\footnotetext{
2 Um localismo globalizado significa a conversão de um determinado fenómeno ou condição com origem local em condição universal capaz de ditar as regras de integração ou exclusão (Santos, 2001: 71; 2008b: 42).

3 Este conceito do filósofo argentino Enrique Dussel aponta o erro de tomar as realidades europeias e norte-americanas como realidades globais. Concebida de fora da Europa e dos Estados Unidos, a falácia do deslocamento é descrita como a falácia de tomar o espaço ou o mundo de uma determinada cultura como se fosse o nosso e, nesse sentido, invisibilizar a distinção original da outra realidade e as diferenças em relação à nossa realidade (Dussel, 2013).

4 A falácia do determinismo nega a possibilidade de alternativas e a falácia do desaparecimento do Sul assenta na recusa em reconhecer hierarquias, bem como a ideia de que o Norte tem a aprender com ○ Sul (Santos, 2005a; 2008b).
} 
isentas de questionamento, dado que a experiência dos indivíduos foi naturalizada a partir do padrão de poder do capitalismo colonial/moderno (Quijano, 2009: 75). Este processo de interiorização da inferioridade, abordado por Frantz Fanon na obra "Peles negras, máscaras brancas" (2008) [1952]), tem sido amplamente reconhecido pelos estudos pós-coloniais mais recentes. Achile Mbembe refere a sedução material, moral e intelectual dos europeus sobre os africanos e argumenta que colonização resulta da violência ocidental apoiada em aliados africanos que colonizavam os seus próprios conterrâneos em nome da nação metropolitana. Nas palavras do autor, "como uma fábrica de ficções refratada e infinitamente reconstituída, o colonialismo gerou mútuas utopias e alucinações partilhadas pelos colonizadores e pelos colonizados". É nesse sentido que Mbembe fala de colonialismo como co-invenção (Mbembe, 2010).

Nelson Maldonado-Torres recorre à ideia de "mito difusionista do vazio", um conceito original de J. M. Blaunt, para mostrar como a ciência europeia não tem em conta o que fica para lá de si própria, concebendo as regiões não-europeias como vazias ou praticamente desabitadas, em que a população residente é nómada, desconhece o conceito de propriedade privada e é alheia à criatividade intelectual e a valores espirituais (Maldonado-Torres, 2009). Um célebre ditado africano sustenta que enquanto os leões não tiverem os seus próprios historiadores, a história glorificará para sempre os caçadores. Neste ditado cabe parte da história da modernidade. Como afirma Mignolo "uma das razões para só se ver metade da história é que esta foi sempre contada do ponto de vista da modernidade" (Mignolo, 2003: 639, 640). O conhecimento difundido é o que serve os vencedores e a máscara de universa- lidade com que se veste é usada para desqualificar outras narrativas, saberes e práticas e, nesse sentido, reproduzir as lógicas de dominação.

A monocultura do saber e do rigor do saber é, segundo Boaventura de Sousa Santos, o modo de produção de não existência mais poderoso. Na definição do autor "consiste na transformação da ciência moderna e da alta cultura em princípios únicos de verdade e qualidade estética". Assim, tudo o que cânone não reconhece, não existe ou é irrelevante. A monocultura da escala dominante é uma consequência direta da monocultura do saber: arrogando-se universal e excluindo o que não se encaixa nos seus padrões, tudo o que é local ou particular é invisibilizado pela lógica da escala global (Santos, 2006). Castro-Gómez designa o modelo epistemológico da modernidade por "hybris do ponto zero". A ciência imagina-se como Deus, situada no ponto zero, o observador que observa $o$ mundo a partir de uma plataforma não observável, com vista a exercer uma observação verdadeira e inquestionável. Quando os mortais querem ser como os Deuses, sem capacidade de o serem, incorrem no pecado da hybris. $O$ ponto zero é a dimensão epistémica do colonialismo, que, como Castro Gomes nota, deve ser entendido como algo constitutivo da modernidade. Foi a ciência moderna que permitiu constituir o imaginário europeu de superioridade e representar e julgar à medida dos seus interesses o resto do mundo, de forma a manipulá-lo, segundo critérios de eficiência e rentabilidade (Castro-Gómez, 2007: 88).

Ao definirem um cânone universal de conhecimento e linguagem a partir da sua experiência particular, a cultura e a ciência ocidentais silenciaram os sujeitos que se exprimem a partir de outras cosmovisões. Porque o epistemicídio e $\circ$ 
linguagicídio os impediram de se representar (e de representar o mundo) nos seus próprios termos, as representações que lhes couberam deram-se por oposição e a diferença foi interpretada como ausência. Nesse processo, inventou-se "o outro", que não é só diferente, é inferior e atrasado, porque aquém. A naturalização desta construção social permitiu legitimar a dominação e a exploração: - outro é o objeto separado do sujeito e por isso é estudável, apropriável, controlável e previsível. A exterioridade, a alteridade é, assim, uma construção extremamente poderosa (Said, 1978; Santos, 1995, 2006; Santos et. al., 2004; Lander, 2005; Quijano, 2009; Escobar, 2003; Hall, 2013; Young, 2009). A lógica da classificação social consiste precisamente na distribuição das populações por categorias que identificam diferença com desigualdade (Santos, 2006). Naturalizando as hierarquias, nega-se a sua intencionalidade e a dominação é vista como consequência e não como causa da hierarquia e pode mesmo ser considerada como uma obrigação ("o fardo do homem branco") (idem).

Obcecada com a ideia de progresso linear, a modernidade é incapaz de conceber opções para lá do metarrelato universal que definiu. $O$ tempo foi colonizado pela Europa, que fez coincidir os eventos que conduziram ao advento da modernidade em solo europeu com estádios históricos alegadamente universais (Maldonaldo-Torres, 2009: 372, 373). As dicotomias em que assenta a compreensão ocidental do mundo são pois nutridas de uma lógica evolucionista, que sobrepõe inferioridade e anacronismo. O outro não é só selvagem, é atrasado, primitivo, arcaico. O padrão civilizacional da modernidade é a imagem do futuro para o resto do mundo, que pode estar mais perto ou mais longe de o alcançar (Lander, 2005; Hall, 2013), mas que o atingiria rapidamente "não fosse por sua composição racial inadequada, sua cultura arcaica ou tradicional, seus preconceitos mágico-religiosos ou, mais recentemente, pelo populismo e por Estados excessivamente intervencionistas, que não respondem à liberdade espontânea do mercado" (Lander, 2005).

Declarando atrasado, arcaico, tudo o que, segundo a norma temporal, é assimétrico em relação ao mundo declarado avançado, produz-se não existência pela "não contemporaneidade do contemporâneo" (Santos, 2006: 96) ou, na linguagem de Johannes Fabian, pela "negação de simultaneidade" (negation of coevalness) (Fabian, 1983). Para Boaventura de Sousa Santos, esta realidade é ilustrada pelo encontro entre o camponês africano e o funcionário do Banco Mundial em trabalho de campo. O camponês não é observado como contemporâneo do funcionário, mas como habitante de um estádio de desenvolvimento anterior, que poderá ser transformado se forem cumpridos os projetos de desenvolvimento. A não existência assume, neste caso, a forma de residualização (Santos, 2006: 96).

A crítica que os estudos subalternos dirigiram ao historicismo prende-se com esta conceção de tempo. Para Chakrabarty, a chegada do historicismo aos não-europeus durante o século XIX tomou a forma de um "ainda não" dirigido ao outro. O historicismo coloca o tempo histórico como medida da distância cultural entre - ocidente e o não ocidente. Nas colónias, legitimou a ideia de civilização. $\mathrm{Na}$ Europa, permitiu desenvolver a narrativa que incorpora unicamente eventos históricos que decorreram no interior das fronteiras europeias e conceber 0 continente como o lugar em que primeiro ocorreu o capitalismo, a modernidade ou o lluminismo. Aos habitantes das colónias foi-lhe atribuído o "outro lugar" na es- 
trutura de tempo concebida nos seguintes termos: "primeiro na Europa, depois noutro lugar" (Chakrabarti, 2000). A frase de John Locke "no princípio todo o mundo foi América" é evocada por Castro-Gómez para ilustrar o imaginário europeu que transformou um caminho particular em etapas que todas as nações devem superar (Castro-Gómez, 2005).

\subsection{O direito como duplo da ciência. Do centralismo jurídico ao pluralismo jurídico}

A vitória do conhecimento científico sobre outras formas de conhecimento, como mencionei, esteve ligada à ascendência do capitalismo. A tarefa de assegurar a ordem exigida pelo capitalismo coube ao direito moderno, "o ersatz que mais se aproximava - pelo menos no momento - da plena cientifização da sociedade que só poderia ser fruto da própria ciência moderna" (Santos, 2000: 111). Nas palavras de Boaventura de Sousa Santos, o direito moderno positivo assenta num "sistema racional de leis, universais e abstractas, emanadas do Estado, que presidem a uma administração burocratizada e profissional e que são aplicadas a toda a sociedade por um tipo de justiça baseado numa racionalidade lógico-formal" (Santos, 2000: 132). Na mesma linha, Wolkmer atribui quatro pressupostos ao direito moderno: estatalidade, unicidade, positivação e racionalidade. $\bigcirc$ sistema jurídico, emanado do Estado, é constituído por um sistema único de normas jurídicas coercivas, estabelecidas oficialmente a partir de um modelo centralizado. É contaminado pela racionalidade própria da lógica de desenvolvimento capitalista que aparece estreitamente ligada à estatalidade, à organização burocrática e ao desenvolvimento jurídico (Wolkmer, 1994: 53-57).
Com a revolução francesa, materializa-se plenamente a ideia de Estado-nação enquanto categoria histórico-política da modernidade burguesa-capitalista. Com vista a legitimar o funcionamento dos novos mercados, proclama-se que é a nação soberana e já não o Príncipe o verdadeiro sujeito de Direito. Os processos de codificação correspondem às necessidades de segurança e estabilidade da burguesia no âmbito do capitalismo concorrencial (Wolkmer, 1994). Os cidadãos e as cidadãs ficaram ligados/as ao processo de produção pela submissão do seu tempo e do seu corpo a leis definidas pelo Estado a partir de uma normatividade cientificamente legitimada (Castro-Gómez, 2005). O direito moderno é, assim, a configuração jurídica que confere a segurança e a previsibilidade necessárias ao projeto moderno, um quadro coeso que pode ser transportado e imposto a outros lugares, promovendo o desaparecimento ou a invisibilização do que fica além dos muros inflexíveis que construiu. A hipótese jurídica centralista foi, assim, uma decisão política convertida em tese hegemónica e o centralismo jurídico converteu-se num "direito tout court" (Santos, 2009).

A ideia de que o Estado detém o monopólio do direito é um mito que começou a ser questionado logo como reação aos movimentos de codificação moderna, mas que ainda hoje ocupa boa parte do nosso imaginário jurídico. Reconhecendo que a narrativa do direito moderno é apenas uma parte da história, esta veio a ser classificada como "centralismo jurídico" (Griffiths J., 1986) ou "monismo jurídico" (Wolkmer, 1994; Higuera e Maldonado, 2007), por oposição ao que ficou conhecido como "pluralismo jurídico". Em meados dos anos 1980, John Griffiths reconhecia no centralismo jurídico uma construção ideológica, segundo a qual "a lei é e deve ser a lei do Estado, uniforme para todas as pessoas, exclusiva de todas as 
outras leis, e administrada por um único conjunto de instituições estatais". De acordo com esta conceção, todas as outras ordens normativas são menores, estão e devem estar subordinadas ao direito e às instituições estatais (Griffiths J., 1986: 3).

Usando a linguagem da cartografia simbólica do direito, desenvolvida por Boaventura de Sousa Santos, o direito moderno definiu o Estado como a escala privilegiada a partir da qual observa o mundo jurídico e o Estado moderno assenta no pressuposto de que o direito opera segundo uma única escala, a escala do Estado. Como disse Eduardo Galeano "até o mapa mente", o mapa em que aprendemos geografia "não mostra o mundo tal como ele é, se não tal como seus donos mandam que seja". A este propósito, Boaventura de Sousa Santos evoca a história narrada por Jorge Luís Borges sobre o imperador que encomendou um mapa exato do seu império, que, sendo do tamanho do império, era impossível de manusear. Como nos mapas geográficos, não é a distorção que configura - problema dos mapas jurídicos modernos, mas a arrogância de conceber um vazio para além do traçado ou a crença de que as opções feitas são as únicas ou as mais relevantes. $O$ enviesamento resulta, pois, da colonialidade jurídica que invisibiliza ou desclassifica a realidade que cabe em mapas jurídicos construídos a partir de escalas diferentes, bem como de outras projeções ou usando outra simbologia (Santos, 1988).

Os estudos do pluralismo jurídico desafiam esta leitura desde há várias décadas, mostrando outras escalas e outras possibilidade de projeção. Reconhecer isto é diferente de afirmar que a hegemonia do direito moderno foi fortemente questionada ou que $\circ$ direito estatal e os tribunais judiciais perderam a centralidade que assumiram ao longo dos últimos dois séculos no imaginário social. Do mesmo modo "que existe um cânone literário que define $o$ que é literatura $e$ o que não é, existe também um cânone jurídico que define o que é direito e o que não é" (Santos 1988b: 165). Mesmo nos circuitos em que o conceito de pluralismo jurídico é aceite, a literatura não supera convictamente a conceção centralista e assenta sobretudo nas relações que o direito não estatal estabelece com o direito estatal (Twinning, 2012). A reflexão e o trabalho empírico no âmbito do pluralismo jurídico proporcionaram um contributo importante. No entanto, há um processo de descolonização epistemológica por realizar. Ainda que esses trabalhos reconheçam a existência de outros direitos e outras estruturas jurídicas para além das modernas, continuam quase sempre a ser analisar o objeto a partir do que o Estado reconhece ou por comparação ao Estado, recorrendo a categorias dicotómicas como formal/informal, tradicional/ moderno, estatal/não estatal. $O$ direito estatal tende a permanecer no centro do mapa e os outros direitos nas margens.

Na segunda metade dos anos 1980', Sally Merry definia dois períodos de estudo do pluralismo jurídico. No primeiro, que apelidou de "pluralismo jurídico clássico", os estudiosos centram-se nas sociedades coloniais e pós-coloniais (Merry, 1988), onde era fácil reconhecer diferentes ordens jurídicas: de um lado, o direito europeu; do outro, os direitos costumeiros dos povos nativos (Santos, 2003a). No segundo, os autores do "novo pluralismo jurídico" aplicam o conceito na análise das sociedades industrializadas do Norte, aprofundando o debate do período anterior (Merry, 1988). Na primeira fase, o pluralismo jurídico desenvolveu-se sobretudo na versão que Griffiths (1986) classificou como "fraca" e não só foi associado a contextos considerados de desenvolvimento inferior, como as normas 
e as instituições costumeiras eram encaradas como estáticas. ${ }^{5}$ Assim, ainda que estes trabalhos possam ampliar o campo de investigação, mostrando que o direito estatal não é o único que existe, não constituem um verdadeiro desafio à monocultura do direito e da justiça, na medida em que não colocam em causa a superioridade do mesmo e reproduzem as lógicas da escala dominante, da classificação social e do tempo linear. Apesar dos desenvolvimentos destes debates, foi só no segundo período, designado por "novo pluralismo jurídico", que os estudos se estenderam também às sociedades industrializadas do Norte e o conceito foi desenvolvido na versão dinâmica e "forte". Autores como Boaventura de Sousa Santos (1988a, 1988b, 1992, 2002), Richard Abel (1982), Sally Engle Merry (1988) ou Marc Galanter (1981, 1983) mostraram não se tratar de um fenómeno exclusivo das sociedades classificadas como menos desenvolvidas, mas uma condição virtualmente existente em qualquer sociedade. $\bigcirc$ alargamento da geografia dos objetos etnográficos permitiu que o pluralismo jurídico fosse perdendo a sua conotação de exotismo e marginalidade. A teoria adquiriu complexidade, uma vez que deixou de ser clara a distinção entre direito imposto e direitos locais, e os direitos começam a ser observados nas suas formas dinâmicas, interativas e mutáveis (Merry, 1988; Santos 2009). Os desenvolvimentos teóricos influenciaram os estudos empíricos quer das socieda-

\footnotetext{
5 Griffiths introduz uma distinção fundamental entre o pluralismo jurídico de sentido fraco e o pluralismo jurídico de sentido forte. $O$ último dá conta da multiplicidade de ordens normativas que coexistem na sociedade, independentemente de serem ou não reconhecidas pelo Estado. Na perspetiva do pluralismo jurídico fraco, um sistema jurídico é plural quando o Estado atribui diferentes ordens normativas a diferentes grupos na população, sendo estes, em regra, definidos a partir de características como a etnia, a religião, a nacionalidade ou a geografia. Os regimes jurídicos paralelos, dependentes do sistema jurídico estatal, resultam do reconhecimento por parte do Estado da alegada preexistência do direito costumeiro dos grupos em causa. Este tipo de pluralismo jurídico está associado essencialmente à experiência colonial e pós-colonial e não é inconsistente com a ideologia do centralismo jurídico. Para Griffiths, é um compromisso que a ideologia do centralismo jurídico se vê obrigada a fazer com a realidade social recalcitrante, isto é, até que as populações heterogéneas e primitivas dos Estados ex-coloniais, no processo de construção do Estado-nação, se transformem em populações homogéneas, à semelhança do previsto para os Estados modernos, é necessário fazer concessões (Griffiths J., 1986: 5-8).
}

des industrializadas do Norte, quer das sociedades pós-coloniais, onde a representação inflexível do direito tradicional passou a ser identificada como mito. ${ }^{6}$

Aos dois períodos de produção de estudos do pluralismo jurídico definidos por Sally Engle Merry, Boaventura de Sousa Santos acrescenta um terceiro, cujo estudo inclui para além das ordens locais e intraestatais, em que os trabalhos dos períodos anteriores se centravam, as ordens jurídicas transnacionais e supra estatais, levando a abordagem da pluralidade jurídica ao espaço global (2003a: 55). Mais do que um alargamento do estudo em termos dos espaços estudados e das ordens normativas envolvidas ao longo destes três períodos, verificou-se um aprofundamento da análise, caminhando-se de uma ideia de ordens normativas que simplesmente coexistem para ordens normativas que se interligam. Nas sociedades contemporâneas, a "porosidade" das ordens jurídicas é cada vez mais intensa e complexa. Com os processos de globalização, aumentaram as ordens jurídicas em presença, bem como as articulações estabelecidas entre elas (Santos, 2003a). Vivemos, então, num "mundo de hibridações jurídicas", resultante do que Santos designa como interlegalidade e se faz sentir tanto ao nível macro, como ao nível ao nível micro, isto é, afeta quer o direito nacional estatal, quer as vivências individuais e a personalidade jurídica dos cidadãos.

O contexto geográfico dos estudos sobre - pluralismo jurídico marca inquestionavelmente as abordagens e as teorias e - desafio passa por articulá-las, sem a exportar de um contexto para outro. Neste artigo, enfatizo as grandes diferenças entre as realidades da América

6 A "invenção da tradição" e parte do debate que se relaciona com esta ques-
tão serão abordados no ponto seguinte e retomados de forma mais pormenoritão serão abordados no pan
zada no segundo capítulo. 
Latina e de África. São poucas as vezes que a literatura se cruza. Isso permite que Boaventura de Sousa Santos, em momentos diferentes, tenha definido de forma dissemelhante o que entende por terceiro período de estudos do pluralismo jurídico: um para o contexto africano (Santos, 2003a) e um para o contexto da América Latina (Santos, 201 1). Neste último, os objetos privilegiados assentam nas mudanças ocorridas nas Constituições da Bolívia e do Equador, os exemplos mais aproximados do ideal de pluralismo jurídico comunitário participativo tal como definido por Wolkmer (Wolkmer, 1994). Em ambos os países, assistiu-se a uma expansão do direito para lá do horizonte liberal do Estado Moderno num processo que tem sido designado por refundação do Estado e em que o reconhecimento do pluralismo jurídico é uma das dimensões de um projeto que envolve o reconhecimento da plurinacionalidade, de autonomias territoriais assimétricas, da democracia intercultural e de novas subjetividades individuais e coletivas.

Estas transformações resultam de um novo processo constitucional protagonizado a partir de baixo pelos excluídos e seus aliados (Santos, 2010b, 2011 ). Perante estes processos, compreendidos como avanços extraordinários para a luta anticapitalista e anticolonial, Boaventura de Sousa Santos, ignora a sua própria inovação teórica que associava o terceiro tipo de pluralismo jurídico aos estudos que envolviam a abordagem das ordens jurídicas locais, nacionais e globais e as complexas situações de hibridismo e interlegalidade, e define o terceiro período de estudos sobre o pluralismo jurídico como o "novíssimo pluralismo jurídico", onde cabem as inovações ocorridas na América Latina, que põem em causa a simetria entre Estado, direito e nação (Santos, 2011 ).
2. A ECOLOGIA DE JUSTIÇAS E A EXPANSÃO DO PENSAMENTO JURÍDICO PLURALISTA. OS CONTEXTOS LATINO-

\section{AMERICANO E AFRICANO}

Refletindo a partir das Epistemologias do Sul, pretendo contribuir para uma leitura renovada de temas clássicos da sociologia e da antropologia do direito, nomeadamente o pluralismo jurídico e as justiças comunitárias. A sociologia das ausências e das emergências é um instrumento central das Epistemologias do Sul. Esta proposta epistemológica parte da ideia de que o que não existe é, na verdade, ativamente produzido como não existente, isto é como uma alternativa não-credível ao que existe, e visa conhecer e credibilizar a diversidade das práticas sociais existentes no mundo face às práticas hegemónicas e pensar o futuro em função dessa dilatação do presente.

A operacionalização da sociologia das ausências é feita pela substituição das monoculturas do conhecimento, que o contraem, por ecologias, que o dilatam. A ecologia de saberes é o instrumento mais forte. Assente na premissa de que todos os saberes são incompletos e que isso se aplica também à ciência, a ecologia de saberes propõe o confronto da monocultura da ciência moderna com o reconhecimento da diversidade de formas de conhecimento que existem no mundo (Santos, 2006, 2007). O processo de reconhecimento de outros saberes, de outras formas de conhecer, envolve necessariamente as restantes ecologias, nomeadamente a rejeição da lógica do tempo linear, da hierarquia da classificação social, da desvalorização do que é local ou do que não encaixa na narrativa da produção capitalista. Enquanto a sociologia das ausências amplia $\circ$ presente, juntando-lhe o que foi subtraído por via da invisibilização, a sociologia das 
emergências move-se no campo das expetativas e pensa o futuro em função desse novo mapa, procedendo a uma ampliação simbólica dos saberes, práticas e agentes, juntando ao real dilatado as possibilidades e expectativas futuras que ele comporta (Santos, 2006: 107-113).

As lentes da sociologia das ausências e das emergências têm sido usadas preferencialmente para abordar o que Santos designou por cosmopolitismo subalterno, isto é, as lutas de movimentos e organizações que resistem ao modelo de globalização hegemónico e à exclusão e reivindicam alternativas (Santos, 2003b, 2005). No âmbito do que podemos designar por uma sociologia jurídica das ausências e das emergências, as Epistemologias do Sul tendem a privilegiar como objeto a "legalidade cosmopolita subalterna", isto é, as estratégias jurídicas em que assenta o cosmopolitismo subalterno ou, por outras palavras, o uso coletivo do direito para promover a globalização contra-hegemónica (Santos e RodriguezGaravito, 2005; Santos, 2005). A legalidade cosmopolita constitui uma estratégia política com uma componente jurídica. As suas lutas articulam os princípios da igualdade e da diferença; combinam o direito não-oficial, com o direito estatal e o direito internacional ou transnacional; assentam em diferentes saberes; e os grupos sociais envolvidos recusam-se a ser vistos como residuais, inferiores, ignorantes, improdutivos, ou apenas locais, reconhecendo no capitalismo e no colonialismo os principais responsáveis pelas suas queixas e a razão da resistência. A legalidade cosmopolita procura tornar o contrato social mais inclusivo, mas também transformá-lo e ampliá-lo (Santos, 2005).

No âmbito do reconhecimento do pluralismo jurídico, a legalidade cosmopolita é identificada nas lutas dos movimentos indígenas da América Latina contra o capitalismo global predatório com base na reivindicação dos direitos locais e dos territórios ancestrais (RodriguezGaravito e Arenas, 2005) e nos já referidos processos de mobilização indígena pelo reconhecimento dos sistemas políticos e jurídicos ancestrais que resultou numa expansão do direito para lá do horizonte liberal do Estado Moderno (Santos e Rodriguez, 2012; Santos e Jiménez, 2012). Referindo-se aos processos de profundas reformas constitucionais que ocorreram no Equador e na Bolívia, Boaventura de Sousa Santos afirma podermos encontrar aí embriões de transformação paradigmática do Estado moderno. Segundo o autor, não se trata apenas do reconhecimento da diversidade cultural ou de um expediente que permita às comunidades locais e remotas resolverem pequenos conflitos no seu interior e garantir a paz social que o Estado não consegue por falta de meios materiais e humanos, mas de conceber a justiça indígena como parte importante de um projeto político de vocação descolonizadora e anticapitalista, uma segunda independência que rompa com os vínculos eurocêntricos que condicionaram os processos de desenvolvimento nos últimos duzentos anos (Santos, 2010b, 2011 e $2012 b)^{7}$

Se estas análises cobrem os fenómenos do terceiro período de estudos do pluralismo na América Latina e são exemplares na ótica de uma sociologia jurídica das emergências, deixam às Epistemologias do Sul - desafio de abordar a realidade que cabe no terceiro período definido para o contexto africano, isto é, o fenómeno da porosidade crescente das ordens jurídicas que conduz a complexas combinações entre direitos locais, nacionais e globais

\footnotetext{
A consagração do princípio do buen vivir em ambas as constituições como paradigma normativo da organização social e económica ou o reconhecimento dos direitos da natureza entendida segundo a consagração indígena de Pachamama são exemplos do que está a construir-se (Santos, 2012 b).
} 
e se faz sentir quer ao nível macro, quer ao nível micro nas estratégias jurídica dos cidadãos e das cidadãs. Nesta ótica, a sociologia jurídica das ausências deve ser levada além das ações coletivas concertadas, da transformação do direito moderno, das lutas através das instituições estatais e das conquistas traduzidas na expansão do Estado liberal e ser usada como instrumento de compreensão da complexidade que se mantem invisibilizada pela linha abissal, isto é, as lutas jurídicas que florescem na interlegalidade e nas lacunas do Estado, as justiças comunitárias que emergem em zonas de contacto entre vários direitos e as estratégias que os cidadãos e as cidadãs usam face à diversidade de ordens jurídica que têm ao dispor numa paisagem híbrida.

O colonialismo africano, sobretudo na versão de governo indireto, assentou num alegado reconhecimento das instituições tradicionais, que na prática significou cooptação e manipulação de autoridades tradicionais e direitos costumeiros e na criação de uma cidadania de segunda para os indígenas. Embora saibamos que $\circ$ que foi designado por "invenção da tradição" tenha sido um processo que envolveu colonos e colonizados e não apenas um movimento imposto de cima para baixo (Mamdani, 1996; Meneses, 2007; Araúio, 2008), no contexto africano, se tivermos que procurar sempre uma cosmovisão ancestral inquestionada para identificar resistência ao direito e à justiça moderna pode suceder que surja a tentação de inventarmos uma ou chegarmos à conclusão de que a resistência é inexistente, irrelevante ou impossível. Do mesmo modo, se por pensamento alternativo entendermos apenas o que nasce nos movimentos sociais organizados de acordo com as nossas categorias analíticas, é possível que continuemos a excluir espaços de luta e resistências que não cabem na moldura das ações coletivas.
É com base nestas leituras que proponho - conceito de ecologia de justiças como instrumento epistemológico para identificar e compreender o espaço e o tempo onde ocorrem lutas individuais, silenciadas, invisíveis que mobilizam direito ou direitos, no Estado, fora do Estado ou em zonas híbridas, que podem contribuir para a transformação das sociedades a partir das expetativas e dos saberes não hegemónicos. Se o direito moderno replicou a colonialidade da ciência moderna, a ecologia de justiças reproduz a lógica da ecologia de saberes.

No âmbito da ampliação dos estudos do pluralismo jurídico e da construção de cartografias jurídicas mais inclusivas, a ecologia de justiças está associada a um conceito de justiças comunitárias amplo e flexível. O objetivo é chegar ao terreno mais resistente à influência de preconceitos, evitar a exclusão de instâncias apenas por não encaixarem numa definição fechada, e ter a possibilidade de dar conta de uma realidade móvel e diversificada, tantas vezes não previsível. O conceito de justiças comunitárias é definido sobretudo pela negativa, por oposição aos tribunais judiciais. Se esta opção pode ser vista como limitação, é a flexibilidade de fronteiras decorrente dessa condição que o torna um instrumento epistemológico relevante. $O$ conceito de justiças comunitárias não tem pretensões de homogeneidade, opondo-se à conceção hegemónica do modelo liberal de justiça - justiça centralizada no Estado, burocrática, hierarquizada, profissionalizada e assente no direito estatal (Santos, 1992: 137), e tem elasticidade suficiente para incluir instâncias esperadas e inesperadas, com formas e significados sociais e políticos altamente diversificados.

Ao contrário dos estudos clássicos do pluralismo jurídico, a ecologia de justiças não procura o exótico ou o tradicional, nem tão 
pouco os meios sancionados como "alternativos" pelo Estado moderno, mas essas e outras estruturas, novas e velhas formas de direito e de justiça, bem como instâncias híbridas que se cruzam em zonas de contacto entre o Estado e a comunidade; quer nos países do Norte, quer nos países do Sul; aquelas que eram esperadas e as que ainda não haviam sido identificadas; deste lado e do outro lado da linha. O objetivo não é desvalorizar nem tão pouco rejeitar o papel do direito estatal, mas reconhecer-lhe a incompletude. Tal como acontece na ecologia de saberes, a ecologia de justiças explora a pluralidade interna do direito, nomeadamente as suas práticas alternativas, e estabelece interações e diálogos horizontais entre formas jurídicas estatais, não estatais e híbridas. O objetivo é a luta contra o desperdício das experiências jurídicas.

Não pretendo romantizar a realidade, mas alargar o cânone do direito, evocando a ideia de copresença radical pela recusa de leituras evolucionistas assentes na monocultura do tempo linear. Pensar a justiça e o acesso ao direito e à justiça por meio de uma ecologia de justiças não equivale a aceitar acriticamente como melhores as práticas que diferem das que são próprias da conceção jurídica moderna, mas, como na ecologia de saberes, colocá-las num espaço em que a sua credibilidade possa ser discutida e argumentada e as suas relações com as experiências hegemónicas possa ser objeto de disputa política (Santos, 2006). O desafio passa por identificar num determinado espaço-tempo quais as instâncias comunitárias que existem e de que modo são usadas pelos cidadãos e pelas cidadãs nas suas estratégias de luta. Amplificar as vozes não organizadas coletivamente, as vozes das lutas travadas no quotidiano é também amplificar o Sul, o seu sofrimento e o conhecimento e a resistência que nascem desse lugar.

\section{A CONSTRUÇÃO DE CARTOGRAFIAS} JURÍDICAS PÓS ABISSAIS. UM EXEMPLO A PARTIR DO CENTRO DA CIDADE DE MAPUTO

À reflexão epistemológica de onde parto correspondem desafios metodológicos. O objetivo da investigação que conduzi na cidade de Maputo prendia-se com a identificação das justiças comunitárias e o estudo do papel que desempenham no acesso à justiça. ${ }^{8}$ Num horizonte mais amplo do trabalho está presente a luta contra o desperdício da experiência jurídica. Importa, pois, que o investigador e a investigadora se libertem de mapas pré-concebidos e se permitam surpreender pelo terreno. Nas próximas páginas, exponho, de forma muito sintetizada, o processo de mapeamento das justiças comunitárias que conduzi no centro urbano da cidade de Maputo, o distrito n. ${ }^{\circ} 1$ ou KaMpfumo.

Estudar as dinâmicas jurídicas moçambicanas constitui um desafio que tem sempre que ir além do ao que a lei prevê, do que os livros de história relatam ou das narrativas oficiais. O país compreende múltiplas paisagens que assentam em combinações jurídicas incompreensíveis nos termos das dicotomias previstas pelo pensamento moderno, como formal e informal ou tradicional e moderno. No presente, as culturas políticas e jurídicas e as estratégias do Estado, presentes e passadas, cruzam-se com as dinâmicas locais e internacionais, constituindo virtualmente, em cada momento e em cada espaço, cenários específicos, tantas vezes surpreendentes. Esta diversidade não é completamente controlada pelo Estado mas não funciona sempre paralelamente às instituições formais. Por um lado, em conformidade com as recomendações

8 O trabalho em Maputo foi realizado entre 2008 e 2010 e assentou sobretudo em entrevistas semi-estruturadas e em observação direta das práticas e das rotinas das instâncias identificadas. 
das instituições internacionais para o desenvolvimento, legislação estatal tem vindo a acolher a pluralidade de lideranças locais que vão funcionando, mesmo que precariamente, como braços através dos quais o Estado se estende. Por outro lado, dada a condição de extrema heterogeneidade do Estado Moçambicano a pluralidade jurídica emerge no seu interior como respostas informais e criativas às necessidades da população que - Estado moderno não previu ou ignora. ${ }^{9}$ Assim, não só o Estado recorre à justiça informal para se expandir, como a comunidade se expande através das estruturas do Estado.

No contexto moçambicano, é frequente os/as investigadores/as optaram pelo estudo de zonas rurais com a expetativa de encontrarem lugares menos contaminados pela modernidade. Ao contrário, escolhi a cidade onde antecipava a inexistência das instâncias mais próximas do imaginário comum sobre as justiças comunitárias, como os tribunais comunitários ou as autoridades tradicionais, e previa encontrar justiças comunitárias híbridas, resultantes do cruzamento de diferentes mundos jurídicos em zonas de contacto. $O$ dualismo entre a cidade de cimento e a cidade de caniço que marcou o espaço colonial ainda hoje se faz sentir ao nível das infraestruturas e do imaginário da população. O distrito de KaMpfumo, quando comparado com os distritos adjacentes, é composto por um número mais elevado de indivíduos que pertencem à sociedade civil íntima e à sociedade civil estranha (Santos, 2003b). É o lugar das universidades, das elites culturais, políticas e económicas cosmopolitas. As justi-

\footnotetext{
9 Boaventura de Sousa Santos distingue o pluralismo jurídico em sentido amplo do pluralismo jurídico interno. $O$ primeiro prende-se com os vários direitos que circulam na sociedade e se interligam; o segundo diz respeito ao pluralismo interno ao Estado e deriva da condição heterogénea do mesmo. A condição de Estado heterogéneo requer a coexistência de diferentes lógicas de regulação executadas por diferentes instituições do Estado com muito pouca comunicação entre si e remete-nos para a imagem de um Estado, cuja atuação vai além do que o próprio define e controla (Santos, 2003).
}

ças comunitárias, ainda que caibam no discurso político nacional, bem como nos estudos e nas recomendações das instituições internacionais enquanto elemento a valorizar no âmbito das políticas de desenvolvimento do país, são vistas como instrumentos de expansão estatal e continuam associadas a cenários de menor desenvolvimento e, de forma não manifesta, a uma justiça de segunda classe. Devem ser usadas lá fora, "nas comunidades", não num espaço "moderno" como o centro da cidade de Maputo.

A especificidade do Distrito de KaMpfumo em relação ao resto do país começou a manifestar-se desde os primeiros passos de preparação da ida para o terreno. Ao estabelecer as estratégias de desenvolvimento do trabalho empírico e no decorrer do trabalho exploratório obtive de vários interlocutores expressões de surpresa, quase de desincentivo, pela área geográfica escolhida, o que não deixou de ser um fator de análise altamente relevante. Não é comum ver um cientista social, que recorra a trabalho etnográfico, escolher KaMmfumo como estudo de caso. Este é visto sobretudo como o espaço do/a investigador/a, das universidades, das livrarias, dos centros de decisão, não dos objetos de investigação. A menos que - tema se prenda com algo que especificamente se encontra na cidade (como elites políticas e económicas, justiça judicial, processos de urbanização), espera-se que a investigadora ou o investigador viaje até aos distritos circundantes e às províncias mais afastadas da capital. No centro urbano cabem as apreciações dos resultados, os debates, bem como os lançamentos de livros. As instâncias comunitárias que integram o imaginário da população, como os tribunais comunitários ou as autoridades tradicionais, não pertencem à paisagem urbanizada do centro da capital, o que está longe de significar que não existem outras com um papel re- 
levante e que são parte do quotidiano de um conjunto alargado de cidadãos e cidadãs. $O$ processo de mapeamento assentou em alguma teimosia e obrigou ao prolongamento do trabalho exploratório muito para lá do tempo inicialmente previsto. Para além das entrevistas planeadas e das que foram surgindo via bola de neve, esta fase passou por percorrer a pé o espaço urbano e bater a múltiplas portas, como a das inúmeras igrejas que existem na cidade. Às entrevistas formais, junta-se uma multiplicidade de encontros e conversas informais.

O mapa final revela que as justiças comunitárias desempenham um papel relevante no centro urbano de KaMfumo, embora este espaço se distinga do que se conhece no restante território e seja composto maioritariamente por híbridos jurídicos, tendo uma relevância muito periférica as dicotomias oficial/não oficial, formal/informal ou tradicional/moderno. Identifiquei quatro tipos de justiças comunitárias: instâncias criadas no âmbito do Estado (heterogéneo); instâncias privadas criadas na esfera do mercado ou da comunidade; instâncias tradicionais e instâncias religiosas. Dada a extrema heterogeneidade estatal, a categoria de instâncias criadas no âmbito do Estado compreende instâncias cuja função de resolução de conflitos foi oficialmente prevista e instâncias mais ou menos híbridas que, situadas em zonas de contacto, desenvolveram o papel de resolução de conflitos para responder às necessidades emergentes indo além do que $\circ$ Estado central legalmente prevê ou as estruturas municipais determinam. Esta categoria integra: o Instituto de Patrocínio e Apoio Judiciário (IPAJ), cuja ação de resolução de conflitos extrajudicial é definida por lei; ○ Centro de Mediação e Arbitragem Laboral (CEMAL); a clínica jurídica que funciona no interior de uma universidade estatal, seguindo os termos da lei estatal e recorrendo a técnicos jurídicos reconhecidos pelo IPAJ; as secretarias de bairro, extensão do Estado na comunidade, cuja escassa regulamentação central e municipal abre espaço a formas de atuação heterogéneas; os Gabinetes de Atendimento à Mulher e Criança Vítimas de Violência, uma instância intermédia entre a família e o Estado; e as esquadras de polícia, o mais intenso dos híbridos jurídicos, uma estrutura de autoridade estatal onde se reproduzem formas de atuação de instâncias classificadas como "tradicionais", "comunitárias" ou "populares". A segunda categoria cobre instâncias criadas por iniciativa privada na esfera do mercado ou no âmbito da comunidade e inclui: as ONGs ou associações congéneres que funcionam sob o pilar da comunidade e acumulam funções de apoio jurídico e resolução de conflitos (Liga dos Direitos Humanos, MULEIDE, AMMCJ, Nós por Exemplo); a clínica jurídica de uma universidade privada que, tal como a clínica jurídica da universidade pública, visa promover o acesso ao direito e à justiça e é por isso uma instância assente no princípio da comunidade, embora seja influenciada pelo pilar do mercado no sentido em que pertence a uma universidade que tem em vista o lucro; e o Centro de Arbitragem, Mediação e Conciliação criado pela Confederação das Associações Económicas de Moçambique, que não tem fins lucrativos mas age no horizonte da promoção de um melhor ambiente de negócios, assentando claramente nos princípios do mercado. A terceira categoria é a das instâncias que se classificam como tradicionais num contexto de crescente afirmação do Estado moderno e inclui apenas a Associação de Médicos Tradicionais (AMETRAMO), que resolve conflitos relacionados com acusações de feitiçaria. A quarta categoria cobre as justiças comunitárias criadas no âmbito de igrejas e comunidades religiosas e assume também uma imensa heterogeneidade. 
conjunto das várias justiças comunitárias configura uma rede de forum shopping de KaMpfumo e, no uso seletivo que os cidadãos fazem das mesmas, contribuem para o acesso ao direito e à justiça. Todas elas proporcionam uma justiça próxima dos cidadãos, economicamente acessível, compreensível e assente em procedimentos flexíveis. No entanto, a proximidade e a flexibilidade assumem significados diferentes. As esquadras da polícia funcionam como paliativo que dá respostas imediatas à procura suprimida, conflitos ignorados pelas estruturas modernas (ou porque ocorrem no mercado informal ou porque envolvem valores muito baixos ou porque não têm enquadramento jurídico), ocorridos entre membros da sociedade civil incivil, numa sociedade atravessada por enormes desigualdades económicas. Não significa que não resolvam conflitos judiciáveis, oferecendo soluções muito mais rápidas do que as dos tribunais, sem envolver qualquer custo, mas não é aí que se encontra o núcleo central de procura.

O Gabinete Modelo de Atendimento à Mulher e Criança Vítimas de Violência e a Associação Nós Por Exemplo resolvem conflitos multidimensionais e complexos. Em ambos os casos, a linguagem e os procedimentos são compreensíveis, mas a abordagem aos litígios é diferente. $O$ Gabinete trata os problemas sem profundidade e não dispõe de capacidade para desafiar a lógica das relações patriarcais. Tratando-se de um espaço com potencial para oferecer respostas rápidas, já que tem a força da autoridade policial, quase nunca promove uma análise aprofundada dos conflitos nas suas várias dimensões. Por outro lado, a Associação, com abordagens mais abrangentes e multidimensionais, promove soluções criativas, extrapolando as fronteiras dos vários direitos, e apresenta uma maior potencialidade para renegociar os papéis impostos pelo patriarcado. ${ }^{10}$

Na lógica de sociologia das emergências, podemos afirmar que os híbridos jurídicos identificados desafiam a colonialidade do direito, isto é, numa lógica de ampliação simbólica dos saberes e práticas. Os cidadãos e as cidadãs apropriam-se das estruturas estatais e não estatais, usando-as seletivamente, e negociando uma legalidade para lá do que o Estado moderno ou as instituições modernas internacionais controlam ou reconhecem, mas desafiando também as normas do direito da comunidade. Como os tribunais judiciais, as justiças comunitárias não são imunes a dificuldades e entraves à democratização e não estão ali para resolver todos os problemas. No entanto, tal como os tribunais judiciais não são excluídos do debate sobre o acesso ao direito e à justiça pelos problemas e pelas dificuldades que enfrentam, as justiças comunitárias, na sua diversidade, devem ser deslocadas da posição marginal que ocupam e ser conduzidas a uma plataforma de discussão horizontal. Por outras palavras, as justiças comunitárias não têm que ser apoiadas ou toleradas apenas para compensar o excesso de litigação dos tribunais judiciais, mas discutidas, observadas nas duas diferenças, e sujeitas à crítica séria com o objetivo de exponenciar as suas potencialidades em função dos contextos onde existem.

\section{CONCLUSÃO}

A reflexão apresentada parte de um objeto clássico da sociologia e da antropo-

10 A maior surpresa da investigação foi a identificação das esquadras da Polícia da República de Moçambique (PRM) como justiças comunitárias. Como a Associação Nós Por Exemplo e o Gabinete Modelo de Atendimento à Mulher e Criança, a PRM foi selecionada para um abordagem micro, um estudo mais extenso e aprofundado por via da observação continuada das práticas e das rotinas. Trata-se de uma instância nascida do Estado heterogéneo com ampla visibilidade, cuja legitimidade tem origem na articulação da autoridade que o Estado moderno Ihe atribui com a rapidez, a flexibilidade e a proximidade humana próprias de justiças comunitárias como os tribunais comunitários ou as autoridades tradicionais. 
logia do direito a que procuro trazer uma leitura renovada recorrendo a uma proposta central às Epistemologias do Sul: a sociologia das ausências e das emergências. No horizonte da investigação, cujos resultados se apresentam de forma muito parcial, está a ambição de contribuir para o alargamento do cânone do direito e da justiça e para a construção de um pensamento jurídico pós-abissal. Esses objetivos envolvem exercícios continuados para aprender a des-pensar as construções modernas que comprimem o pensamento jurídico.

A sociologia das ausências e das emergências tem dado especial atenção ao que foi definido por cosmopolitismo subalterno e a sociologia jurídica das ausências tende a privilegiar como objeto a "legalidade cosmopolita subalterna". O que defendi é a necessidade de expandir o campo da realidade tornada visível. O projeto de rompimento total com a linha abissal exige a inclusão de espaços de luta organizados em termos que não cabem nas categorias conhecidas de emancipação social. Trata-se de um desafio muito complexo, visto que não ser fácil reconhecê-los, compreender em que medida se constroem como resistências. O conceito de ecologia de justiças para mapear as justiças comunitárias é apenas um contributo para enfrentar esse desafio, que envolve ainda a questão de como criar inteligibilidade entre mecanismos e espaços de luta tão heterogéneos de forma a construir redes de solidariedade mais amplas que desafiem a hegemonia global do colonialismo, do capitalismo e do patriarcado.

O repto que as Epistemologias do Sul lançam à sociologia do direito é muito maior do que o campo individual de uma investigação ou reflexão e envolve um projeto coletivo e continuado que não se traduz em outputs científicos e assenta em processos de co-aprendizagem e produção coletiva de conhecimento a partir de práticas e saberes diversos. Esta investigação constitui um exercício parcial que pretendeu conhecer e mostrar alguma da diversidade jurídica. Ir mais além implica promover diálogos entre o Sul e o Norte, entre pessoas reais na diversidade das suas experiências, que resultem em lições partilhadas num horizonte de transformação do futuro.

\section{BIBLIOGRAFIA}

Abel, Richard (1982),"'Introduction". In Abel, Richard (org.), The Politics of informal justice. New York: Academic Press.

Araújo, Sara (2008), "Pluralismo jurídico em África. Ficção ou realidade?", Revista Crítica de Ciências Sociais, 83, 121-139.

Castro-Gómez, Santiago (2005), "Ciências sociais, violência epistêmica e o problema da 'invenção do outro"'. In Lander, Edgardo (org), A colonialidade do saber: eurocentrismo e ciências sociais. Perspectivas latino-americanas. Ciudad Autónoma de Buenos Aires: Colección Sur Sur, CLACSO. Disponível em http://biblioteca.clacso.edu.ar/ar/ libros/lander/pt/lander.html [acedido em maio de 2013].

Castro-Gómez, Santiago (2007), "Decolonizar la universidad. La hybris del punto cero y diálogo de saberes". In Castro-Gómez, Santiago \& Grosfoguel, Ramón (org.), El giro decolonial. Reflexiones para una diversidad epistémica más allá del capitalismo global. Bogotá: Siglo del Hombre Editores, Universidad Central-Instituto de Estudios Sociales Contemporáneos y Pontificia Universidad Javeriana-Instituto Pensar.

Chakrabarty, Dipesh (2000), Provincializing Europe. Poscolonial Tough and Historican Difference. Princeton: Princeton University Press.

Dussel, Enrique (2013), "Agenda for a South-South Philosophical Dialogue", Human Architecture: Journal of Sociology of Self-Knowledge, xi (1), 3-18.

Ehrlich, Eugen (1979), "Living Law". In Campbell, Colin \& Willes, Paul (org.), Law and Society. Readings in the sociology of law. Oxford: Martin Robertson \& Co. Ltd. [Fundamental principles of the 
sociology of law (1912), Cambridge: Mass, Harvard University Press (1936), 61-74, 486-93].

Escobar, Arturo (2003), "'Mundos y conocimientos de outro Modo'. El programa de investigación de modernidad/colonialidade latino-americano", Tabula Rasa, 1, 51-86.

Fabian, Johannes (1983), Time and the Other. How Anthropology Makes its Object. New York: Columbia University.

Fanon, Frantz (2008 [1952]), Black Skin. White Masks. New York: Grove Press.

Galanter, Marc (1966), "The modernization of law". In Winer, Miron (org.), Modernization.

New York: Basic Books.

Galanter, Marc (1981), "Justice in Many Rooms: Courts, Private Ordering and Indigenous Law", Journal of Legal Pluralism and Unofficial Law, 19, $1-47$.

Galanter, Marc (1983), "Reading the landscape of disputes: what we know and don't know (and think we know) about our allegedly contentious and litigious society", UCLA Law Review, 31 (4), 4-71.

Griffiths, John (1986), "What is Legal Pluralism?", Journal of Legal Pluralism, 24, 1-55.

Hall, Stuart (2013 [1992]), "Occidente y el resto: discurso y poder". In Sulca, Ricardo Soto (org.), Discurso y Poder en Stuart Hall. Huancayo: Ricardo Soto Sulca.

Hespanha, António Manuel (1993), Justiça e Litigiosidade: História e Prospectiva. Lisboa: Fundação Calouste Gulbenkian.

Hespanha, António Manuel (2007), O Caleidoscópio do Direito e da Justice nos dias e no mundo de hoje. Coimbra: Almedina.

Higuera, Libardo Ariza \& Maldonado, Daniel Bonilla (2007), "El pluralismo jurídico. Contribuciones, debilidades y retos de un concepto polémico". In Higuera, Libardo Ariza \& Maldonado, Daniel Bonilla (org.), Pluralismo Jurídico. Bogotá: Siglo del Hombre Editores, Universidad de los Andes, Pontifícia Universidad Javeriana.

Janse, Ronald (2013), "A Turn to Legal Pluralism in Rule of Law Promotion?", Erasmus Law Review, $6(3 / 4)$.
Lander, Edgardo (2005), "Ciências sociais: saberes coloniais e eurocêntricos". In Lander, Eduardo (org.), A colonialidade do saber: eurocentrismo e ciências sociais. Perspectivas latino-americanas. Ciudad Autónoma de Buenos Aires: Colección Sur Sur, CLACSO.

Maldonado-Torres, Nelson (2009), "A topologia do ser e a geopolítica do conhecimento: modernidade, império e colonialidade". In Santos, Boaventura de Sousa \& Meneses, Maria Paula, Epistemologias do Sul. Coimbra: Almedina.

Mamdani, Mamhood (1996), Citizen and Subject. Contemporary Africa and the legacy of late colonialism. Princeton, New Jersey: Princepton University Press.

Mbembe, Achille (2010), "Formas Africanas Da Escrita De Si", Artafrica, Artigos do trimestre, Centro de Estudos Comparatistas, Faculdade de Letras da Universidade de Lisboa. Disponível em http://www.artafrica.info/html/artigotrimestre/ artigo.php?id=21 [acedido em maio de 2013].

Meneses, Maria Paula (2007), "Pluralism, Law and Citizenship in Mozambique", Oficina do CES, 291. Coimbra: CES.

Merry, Sally Engle (1988), "Legal Pluralism", Law and Society Review, 22 (5), 869-896.

Mignolo, Walter D. (2003), "Os esplendores e as misérias da "ciência": colonialidade, geopolítica do conhecimento e pluri-versalidade epistémica". In Santos, Boaventura de Sousa (org.), Conhecimento Prudente para uma Vida Decente. Um discurso sobre as ciências reinventado. Porto: AfrontamentoQuijano, 2009: 75).

Mudimbe, V. Y. (1988), The invention of Africa. Gnosis, philosophy and the order of knowledge. London: Indiana University Press.

Quijano, Aníbal (2009), "Colonialidade do poder e classificação social". In Santos, Boaventura de Sousa \& Meneses, Maria Paula (org.), Epistemologias do Sul. Coimbra: Almedina.

Rodriguez-Garavito, César \& Arenas, Luís Carlos (2005), "Indigenous rights, transnational activism, and legal mobilization: the stuggle of the U'wa people in Colombia". In Santos, Boaventura de Sousa \& Rodriguez-Garavito César (org.), Law and Globalization from Below. New York: Cambridge University Press. 
Said, Edward (1978), Orientalism. New York: Vintage Books.

Santos, Boaventura de Sousa \& Jiménez, Agustín Grijalva (2012) (org.), Justicia indígena, plurinacionalidad e interculturalidad en Ecuador. Quito: Ediciones Abya Yala e Fundación Rosa Luxemburg.

Santos, Boaventura de Sousa \& Meneses, Maria Paula (2009), "Introdução". In Santos, Boaventura de Sousa \& Meneses, Maria Paula (org.), Epistemologias do Sul. Coimbra: Almedina

Santos, Boaventura de Sousa \& Nunes, João Arriscado (2004), "Para ampliar o cânone do reconhecimento, da diferença e da igualdade". In Santos, Boaventura de Sousa (org.), Reconhecer para libertar. Os caminhos do cosmopolitismo multicultural. Porto: Afrontamento.

Santos, Boaventura de Sousa \& Rodríguez, José Luis Exeni (2012) (org.). Justicia indígena, plurinacionalidad e interculturalidad en Bolivia. Quito: Ediciones Abya Yala e Fundación Rosa Luxemburg.

Santos, Boaventura de Sousa (1988a), O Discurso e o Poder. Ensaio sobre a sociologia da retórica jurídica. Porto Alegre: Sergio Antonio Fabris.

Santos, Boaventura de Sousa (1988b), "Uma cartografia simbólica das representações sociais: prolegómenos a uma concepção pós-moderna do direito", Revista Crítica de Ciências Sociais, 139-172.

Santos, Boaventura de Sousa (1992), "State, Law and Community in the world system: An Introduction", Social \& Legal Studies, 1 (2), 143-159.

Santos, Boaventura de Sousa (1995), Towards a New Common Sense. Law, science and politics in the paradigmatic transition. New York, London: Routledge.

Santos, Boaventura de Sousa (2000), A Crítica da Razão Indolente. Contra o desperdício da experiência. Porto: Edições Afrontamento.

Santos, Boaventura de Sousa (2001), "Os processos da globalização". In Santos, Boaventura de Sousa (org.), Globalização. Fatalidade ou Utopia?. Porto: Edições Afrontamento.

Santos, Boaventura de Sousa (2002), Towards a New Legal Common Sense. London: Butterwords.
Santos, Boaventura de Sousa (2003), "O Estado heterogéneo e o pluralismo jurídico". In Santos, Boaventura de Sousa \& Trindade, João Carlos (org.), Conflito e Transformação Social: Uma Paisagem das Justiças em Moçambique. Porto: Afrontamento

Santos, Boaventura de Sousa (2003b), "Poderá o direito ser emancipatório?", Revista Crítica de Ciências Sociais, 65, 3-76.

Santos, Boaventura de Sousa (2005), "A crítica da governação neoliberal: O Fórum Social Mundial como política e legalidade cosmopolita subalterna", Revista Crítica de Ciências Sociais, 72, 7-44.

Santos, Boaventura de Sousa (2006), A gramática do tempo. Para uma nova cultura política. Porto: Edições Afrontamento

Santos, Boaventura de Sousa (2007), "Para além do Pensamento Abissal: Das linhas globais a uma ecologia de saberes", Revista Crítica de Ciências Sociais, 78, 3-6.

Santos, Boaventura de Sousa (2008), "Os Processos da Globalização", Eurozine. Disponível em: http://www.eurozine.com/articles/2002-08-22santos-pt.html [acedido em junho de 2012]

Santos, Boaventura de Sousa (2009), Sociología Jurídica Crítica. Madrid: Trotta.

Santos, Boaventura de Sousa (2010a), "From the Postmodern to the Postcolonial - and Beyond Both". In Encarnación Gutiérrez Rodríguez; Boatcã, Manuela; Costa, Sérgio (org.), Decolonizing European Sociology. Farnham e Burlington: Ashgate

Santos, Boaventura de Sousa (2010b), Refundación del Estado en América Latina. Perspectivas desde una epistemoloía del Sur. Quito: Abya Yala

Santos, Boaventura de Sousa (201 1), Para uma revolução democrática da justiça. São Paulo: Cortez.

Santos, Boaventura de Sousa (2012a), "Public Sphere and Epistemologies of the South", Africa Development, XXXVII (1), 43-67.

Santos, Boaventura de Sousa (2012b), "Cuando los excluidos tienen Derecho: justicia indígena, plurinacionalidad e interculturalidade". In Santos, Boaventura de Sousa \& Jiménez, Agustín Grijalva, Justicia indígena, plurinacionalidad e interculturalidad en Ecuador. Quito: Ediciones Abya Yala e Fundación Rosa Luxemburg. 
Spivak, Gayatri Chakravorty (1988), "Can the Subaltern Speak?". In Nelson, Cary \& Grossberg, Lawrence (org.), Marxism and the Interpretation of Culture. London: Macmillan.

Twinning, William (2012), "Legal Pluralism 101". In Tamanaha, Brian; Sage, Caroline; Woolcock, Michael (org.), Legal Pluralism and Development. Scholars and Practitioners in Dialogue. Cambridge, New York, Melbourne, Madrid, Cape Town, Sin- gapore, São Paulo, Delhi, Mexico City: Cambridge University Press.

Wolkmer, Antônio Carlos (1994), Pluralismo Jurídico. Fundamentos de uma nova cultura do direito. São Paulo: Editora Alfa Omega.

Young, Robert J. C. (2009), "What is the postcolonial?", Ariel,40 (1). 